\title{
Procedural advantages of a novel coronary stent design with ultra-thin struts and bioabsorbable abluminal polymer coating in an all-comers registry
}

\author{
Haitham Abu Sharar, Bruna Gomes, Emmanuel Chorianopoulos, Ziya Kaya, Christian A. Gleissner, \\ Hugo A. Katus, Raffi Bekeredjian
}

Department of Cardiology, Angiology and Pneumology, Heidelberg University Hospital, Heidelberg, Germany

Adv Interv Cardiol 2018; 14, 3 (53): 240-246

DOI: https://doi.org/10.5114/aic.2018.78326

\begin{abstract}
A bstract
Introduction: The implications of novel drug-eluting stent (DES) design modifications including ultra-thin struts and new concepts of polymer coating for procedural efficacy are still unknown.

Aim: To evaluate procedural efficacy and short-term safety of a novel DES design.

Material and methods: In this all-comers registry, 407 consecutive patients were enrolled upon undergoing percutaneous coronary interventions $(\mathrm{PCI})$ with the thin-strut bioabsorbable abluminal polymer-coated SYNERGY stent. These patients were then compared with the previous 407 patients undergoing PCI performed by the same interventionalists using currently established second-generation DES (Promus Element plus, Xience prime, Resolute Integrity). Several clinical and procedural data were compared, and the coronary artery complexity was assessed by the American College of Cardiology/American Heart Association classification and SYNTAX Score.

Results: The study population consisted of 814 patients. A total of 859 Synergy stents were deployed in 480 target vessels in the Synergy group $(n=407)$, and 904 stents in 469 vessels in the second-generation DES group $(n=407)$. Coincidentally, target lesions in the Synergy group (A 2.7\%, B1 13.8\%, B2 38.6\%, C 45.0\%) were more complex $(p<0.01)$ than those in the second-generation DES group (A 4.9\%, B1 18.7\%, B2 42.3\%, C 34.2\%). In cases with severe lesions (B2/C), the median contrast agent amount and fluoroscopy time were significantly lower in the Synergy group, indicating improved deliverability $(110 \mathrm{ml} v \mathrm{vs} .150 \mathrm{ml} ; p<0.01$ and $7.2 \mathrm{~min}$ vs. $9.1 \mathrm{~min} ; p=0.01$ ). Rates of in-hospital major adverse cardiovascular events were comparable between the two groups.

Conclusions: In an all-comers, real-world PCI population, novel stent design modifications including ultra-thin struts and abluminal bioabsorbable polymer coating are associated with improved procedural performance.
\end{abstract}

Key words: coronary artery disease, percutaneous coronary intervention, drug-eluting stent, stent design, bioabsorbable polymer.

Su m m a ry

In an all-comers registry, novel drug-eluting stent design advances including ultra-thin struts and bioabsorbable abluminal polymer coating are associated with improved stent deliverability and enhanced procedural performance as reflected by significantly lower contrast agent consumption and shorter fluoroscopy time in comparison to currently established $2^{\text {nd }}$ generation drug-eluting stents with comparable rates of in-hospital major adverse cardiovascular events between both groups. This may positively impact our interventional performance in daily practice, patients' safety, and economic efficiency.

\section{Introduction}

During the last 2 decades, coronary stents undergone various improvements, including changes in stent platform design, metal composition, delivery catheter, balloon, polymer coating, and drug loading. In the early stent era, outcome data, including restenosis and stent thrombosis (ST), were the focus of new stent designs. Stent strut geometry showed an impact on stent performance as well as on angiographic and clinical outcomes [1-5]. Early generation bare-metal stents (BMS) with thick-

\section{Corresponding author:}

Haitham Abu Sharar PhD, Department of Cardiology, Angiology and Pneumology, Heidelberg University Hospital, Im Neuenheimer Feld 410, 69120 Heidelberg, Germany, phone: +49 62215636789, e-mail: haitham.abusharar@med.uni-heidelberg.de

Received: 19.02 .2018 , accepted: 6.05 .2018 . 
er stent struts and larger surface contact area with the coronary arteries were related to higher rates of trauma of the internal elastic lamina and media, eventually inducing peri-strut inflammation, neo-intimal proliferation and in-stent stenosis [6, 7]. First-generation drug-eluting stents (DES) showed superiority compared to BMS in terms of target vessel revascularization and major adverse cardiac events (MACE) [8, 9], leading to adoption of DES as a primary choice for percutaneous coronary interventions $(\mathrm{PCl})$. Nevertheless, there were safety concerns regarding increased rates of ST [10-12], most likely due to drugs and polymers used in the first-generation DES $[13,14]$. Thus, second-generation DES were developed including different polymer coatings, different anti-proliferative drugs and enhanced stent platforms, with better clinical results [15]. However, durable polymer coatings were suggested to be a potential source of late (30 days to 1 year) and very late (after 1 year) ST due to prolonged or chronic inflammation [13, 14, 16, 17].

Due to these limitations and because of increasing complex interventions, new DES design modifications were developed with even thinner struts and changes in polymer coating. These novel stent features not only address an improvement in clinical outcome, but shift their focus to safety and simplicity of the procedure, to the increasing demand for suitable stents in very complex and multi-vessel interventions and even to economic efficiency.

The coronary stent which is the focus of this study (Synergy) belongs to this new generation of DES featuring ultra-thin struts as well as reduced bioabsorbable polymer load only to the abluminal side. Several studies have already demonstrated the safety and comparability of these stent innovations in clinical outcome data compared to common second-generation drug-eluting stents [18-20]. However, proof of procedural superiority is still lacking.

\section{Aim}

This study aimed at evaluating procedural efficacy and short-time safety of those recent stent design advances including ultra-thin struts and bioabsorbable abluminal polymer in comparison with currently established second-generation DES in an all-comers registry.

\section{Material and methods}

\section{Study design}

The Synergy stent has been available at our institution since August 2013. Initially, it was solely used as a bailout stent. This all-comers study was prospectively initiated in January 2015, starting to exclusively use the Synergy stent in patients receiving $\mathrm{PCl}$. To avoid any training-related bias, only the 4 most experienced interventional cardiologists participated in this study. They were randomly assigned to various days, performing $\mathrm{PCl}$ with the Synergy stent only. Patient recruitment was finalized in December 2015 after enrolling a minimum of 400 patients in the Synergy group. We then retrospectively collected the same number of patients who previously received $\mathrm{PCl}$ by the same interventional cardiologists just before January 2015. During that period (January 2014 to December 2014), the same interventionalists were also randomly assigned to various days, performing $\mathrm{PCI}$ with established second-generation DES, including PROMUS Element plus (Boston Scientific Corp., Natick, Massachusetts), XIENCE prime (Abbott Vascular, Santa Clara, California), and RESOLUTE Integrity (Medtronic Cardiovascular, Santa Rosa, California). Patients who received a BMS or scaffold were excluded. However, with less than 10 such patients, this number was negligible.

All $\mathrm{PCl}$ decisions were made for symptomatic patients with $\geq 75 \%$ stenosis, or with positive tests including stress echocardiography, stress cardiac magnetic resonance imaging, abnormal fractional flow reserve, or with signs of myocardial infarction. Percutaneous coronary intervention strategies and techniques as well as choice of guide wires, balloons and second-generation DES were left at the discretion of the interventionalist. The reference vessel diameter of treated coronary lesions ranges between $2.25 \mathrm{~mm}$ and $4.0 \mathrm{~mm}$.

To evaluate procedural performance, major endpoints were contrast agent use, fluoroscopy time, and dose area product (DAP). Minor endpoints were in-hospital major adverse cardiac and cerebrovascular event (MACCE) rates, number of balloons prior to stent implantation and the use of additional wires ("buddy wire"). Parameters such as fluoroscopy time, contrast agent consumption and DAP were only assessed for the $\mathrm{PCl}$ and not for the preceding diagnostic angiography (starting with the change of the sheath or introduction of a guiding catheter).

The study was performed in accordance with the Helsinki Declaration and was approved by the local ethics board. Patients provided written consent for every procedure included in this study. Clinical trial registration (http://www.clinicaltrials.gov) unique identifier NCT02881216.

\section{Study device}

The SYNERGY coronary stent (Boston Scientific Corporation, Massachusetts, USA) is a thin-strut $(74-81 \mu \mathrm{m})$ platinum-chromium stent platform delivering everolimus from an ultrathin $(4 \mu \mathrm{m})$ bioabsorbable poly-lactic-co-glycolic acid (PLGA) polymer coating applied only to the abluminal (i.e. outer surface) side of the stent [18]. Endothelialization was reported to be complete within 4 weeks after stent implantation in a porcine coronary artery model [21], whereas the polymer degrades into carbon dioxide and water within 4 months [18], leaving a bare-metal platform behind. 


\section{Complexity of coronary artery disease}

Coronary artery lesions were categorized according to the American College of Cardiology/American Heart Association (ACC/AHA) classification. The extent of the coronary artery disease (CAD) was reflected by calculation of the SYNTAX Score. All diagnostic coronary angiograms in this study were scored according to the SYNTAX Score algorithm and were grouped into pre-specified categories indicating low (0-22 points), intermediate (23-32 points) and high ( $\geq 33$ points) risk [22]. A higher SYNTAX Score is indicative of a more complex CAD. Since some patients had previous bypass surgery, prohibiting SYNTAX score calculation, and since the overall SYNTAX score also includes lesions that were not necessarily treated in the same setting, a lesion-specific "pathway" score was calculated, which would characterize the challenge of deploying a stent to the target coronary lesion.

\section{Statistical analysis}

Continuous data were reported as means ( \pm standard deviation - SD) or medians (interquartile range - IQR) if not normally distributed (Kolmogorov-Smirnov test). Group comparison was done either by the $t$ test or by the two-tailed Mann-Whitney test as appropriate. Categorical variables were expressed as absolute numbers (percentages) and were tested using the $\chi^{2}$ or Fisher's exact test. All tests were 2 -tailed and $p$-values $<0.050$ were considered statistically significant. Statistical analysis and creation of figures were carried out using MedCalc software (Version 16.4.3).

\section{Results}

The study population consisted of 814 patients, with 407 patients in each study arm. Age and gender distribution was similar in both groups (Synergy group: 71 (62-78) years, $74.9 \%$ male; DES group: 72 (62-78) years, $76.9 \%$ male). A total of 859 Synergy stents were deployed in 480 target vessels in the Synergy group, and 904 stents in 469 vessels in the second-generation DES group. Coincidentally, target lesions in the Synergy group (A $2.7 \%$, B1 $13.8 \%$, B2 38.6\%, C 45.0\%) were significantly more complex $(p<0.01)$ than those in the second-generation DES group (A 4.9\%, B1 18.7\%, B2 42.3\%, C 34.2\%), while the median SYNTAX score for "pathway" to lesion was comparable in both groups (11 vs. 10 points, $p=0.17$ ). Significantly more patients in the Synergy group had previous bypass surgery $(18.2 \%$ vs. $11.5 \% ; p<0.01)$. Fewer ST-elevation myocardial infarctions (STEMI) but considerably more cases of non-ST-elevation acute coronary syndrome (NSTE-ACS) were treated in the Synergy group (Tables I and II).

Major endpoints of this study were amount of contrast agent consumed, fluoroscopy time and DAP as surrogate parameters for procedural simplicity of $\mathrm{PCl}$. Interestingly, despite coincidentally more complex coronary lesions in the Synergy group, median contrast agent use and median DAP were significantly lower in the Synergy group (Contrast agent: Synergy $100(70-170) \mathrm{ml}$ vs. second-generation DES 120 (90-200) $\mathrm{ml} ; p<0.01$. DAP: Synergy 29.3 (14-52) Gy $\cdot \mathrm{cm}^{2}$ vs. second-generation DES 36.8 (14-52) Gy $\cdot \mathrm{cm}^{2} ; p<0.01$ ). Fluoroscopy time was non-significantly shorter in the Synergy group. Looking at the subgroup of the most complex lesions (B2 or C lesions), these procedural advantages for the Synergy stent were even more pronounced, reaching statistical significance even for a lower fluoroscopy time in the Synergy group (Contrast agent: Synergy $110(100-120) \mathrm{ml}$ vs. second-generation DES 150 (120-160) $\mathrm{ml} ; p<0.01$. Fluoroscopy time: Synergy $7.2(4.45-14) \mathrm{min}$ vs. second-generation DES 9.1 (8.17-10.63) min; $p<0.01$. DAP: Synergy $31.9(16-56) \mathrm{Gy} \cdot \mathrm{cm}^{2}$ vs. second-generation DES 40 (25-70) Gy $\left.\cdot \mathrm{cm}^{2} ; p<0.01\right)$ (Figure 1; Table III).

To further understand the potential for easier deployment of the Synergy stent, lesion preparation and use of coronary wires were analyzed. Despite more complex lesions in the Synergy group, significantly fewer "buddy wires" were used (Synergy 17.9\% vs. second-generation

Table I. Baseline characteristics

\begin{tabular}{lcccc} 
Parameter & Study population & Synergy & Control & $P$-value \\
\hline Study population, $N$ & 814 & 407 & 407 & 0.51 \\
\hline Male, $n(\%)$ & $618(75.9)$ & $305(74.9)$ & $313(76.9)$ & 0.97 \\
\hline Age, median (IQR) [years] & $72(62-78)$ & $71(62-78)$ & $72(62-78)$ & $<0.01$ \\
\hline Previous CABG, $n$ (\%) & $121(14.9)$ & $74(18.2)$ & $47(11.5)$ & $<0.01$ \\
\hline $\begin{array}{l}\text { Procedure indication, } n(\%): \\
\text { STEMI }\end{array}$ & $123(15.1)$ & $45(11.1)$ & $130(19.2)$ & $199(48.9)$ \\
\hline NSTE-ACS & $335(41.2)$ & $205(50.4)$ & $157(38.6)$ &
\end{tabular}

CABG - coronary artery bypass grafting, CAD - coronary artery disease, IQR - interquartile range, NSTE-ACS - non-ST-elevation acute coronary syndrome, STEMI - ST-elevation myocardial infarction. 
Table II. Classification of coronary artery lesions

\begin{tabular}{|c|c|c|c|c|}
\hline Variable & Study population & Synergy & Control & $P$-value \\
\hline Target vessel: & $(n=949)$ & $(n=480)$ & $(n=469)$ & \\
\hline Right coronary artery & $261(27.5)$ & $126(26.3)$ & $135(28.8)$ & 0.02 \\
\hline Left anterior descending artery & $361(38.0)$ & $179(37.3)$ & $182(38.8)$ & $<0.01$ \\
\hline Circumflex coronary artery & $210(22.1)$ & $103(21.5)$ & $107(22.8)$ & 0.75 \\
\hline Left main & $79(8.3)$ & $48(10.0)$ & $31(6.6)$ & 0.04 \\
\hline Coronary artery graft & $38(4.0)$ & $24(5.0)$ & $14(3.0)$ & 0.10 \\
\hline \multicolumn{5}{|l|}{ Syntax score: } \\
\hline Target lesion, median (IQR) & $10(5.0-17.0)$ & $10(5.0-17.5)$ & $10(5.0-17.0)$ & 0.65 \\
\hline Lesion "pathway", median (IQR) & $11(5-17)$ & $11(5-18)$ & $10(5-17)$ & 0.17 \\
\hline Total CAD score*, median (IQR) & $22.0(14-32)$ & $22(13-33)$ & $23(21-24)$ & 0.94 \\
\hline Risk category 1, $n$ (\%) & $351(43.1)$ & $175(43.0)$ & $176(43.2)$ & 0.05 \\
\hline Risk category 2, n (\%) & $171(21.0)$ & 73 (17.9) & $98(24.1)$ & \\
\hline Risk category 3, $n$ (\%) & $292(35.9)$ & $159(39.1)$ & $133(32.7)$ & \\
\hline \multicolumn{5}{|l|}{ ACC/AHA classification, $n(\%)$ : } \\
\hline Coronary lesion type A & $31(3.8)$ & $11(2.7)$ & $20(4.9)$ & $<0.01$ \\
\hline Coronary lesion type B1 & $132(16.2)$ & $56(13.8)$ & 76 (18.7) & \\
\hline Coronary lesion type B2 & $329(40.4)$ & $157(38.6)$ & $172(42.3)$ & \\
\hline Coronary lesion type C & 322 (39.6) & $183(45.0)$ & $139(34.2)$ & \\
\hline
\end{tabular}

*Excluding CABG patients, IQR - interquartile range, $C A D$ - coronary artery disease.

DES 23.6\%; $p=0.04$ ), fewer "jailed" wire techniques were applied (Synergy $8.4 \%$ vs. second-generation DES $15.2 \% ; p<0.01)$, and significantly more direct stent implantations without predilatation were achieved (Synergy $14.7 \%$ vs. second-generation DES $6.9 \%$; $p<0.01$ ). No significant differences between the groups were seen in the number of bifurcation stentings and the percentage of a successful final "kissing-balloon" technique. The mean stent length was similar with $20 \pm 8.8 \mathrm{~mm}$ for Synergy and $19.5 \pm 8.4 \mathrm{~mm}$ for second-generation DES.

In-hospital short-term MACCE rates were comparable between the two groups (Table IV).

\section{Discussion}

The development of second-generation DES has led to significant clinical improvements [15]. Today, several such second-generation DES are established in interventional coronary therapy, with excellent clinical results. The advances in newer coronary stent designs, with even lower profiles and increased flexibility, may have a positive impact on long-term clinical outcome. However, from a strictly procedural perspective, advantages of newer stent design modifications are expected, but limited data are presently available. A recent study demonstrated superior clinical 1-year outcomes in a cohort utilizing contemporary diagnostic and $\mathrm{PCl}$ methods, including implantation of thin strut bioresorbable-polymer DES, after heart team derived decision making based on the SYNTAX II algorithm [23]. Further investigations are expected in the coming years.

In this all-comers registry, we compared procedural parameters of established second-generation DES with the Synergy stent, representing the new generation of DES with a lower profile. The expected enhanced deliverability of this new stent is based on several changes to its design, including thinner stent struts and only abluminal polymer coating. To prove the procedural advantages, we chose contrast agent use, fluoroscopy time and DAP as major endpoints, since easy stent deployment should be recognized by short procedure time and less need of filming.

Despite coincidental more complex coronary lesions in the Synergy group, both contrast agent consumption and DAP were significantly lower for the patients treated with the Synergy stent, suggesting robust data and reliable procedural benefits. In the subgroup analysis of the most complex coronary lesions, the advantages of the Synergy stent were more pronounced, with significantly lower levels even for fluoroscopy time. This seems plausible, since in a simple lesion, a stent can be easily and perfectly deployed. However, with more complex lesions differences in stent deliverability will become more no- 
A

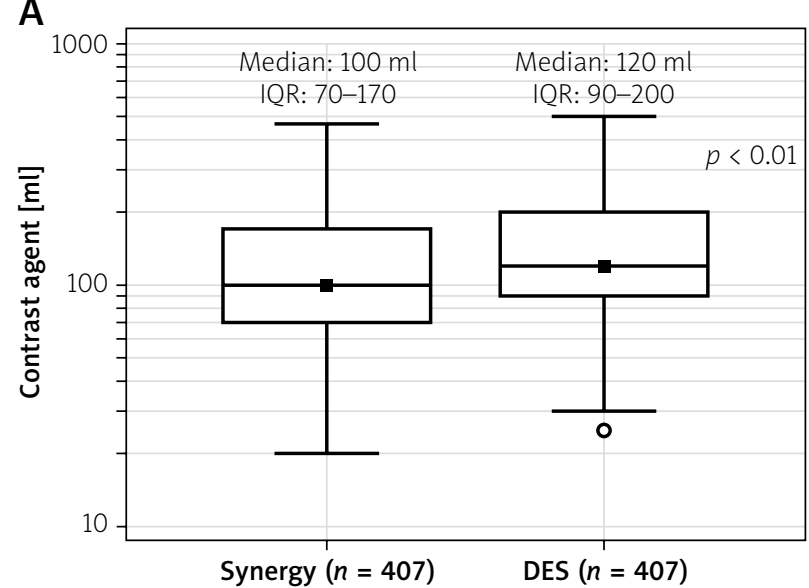

C

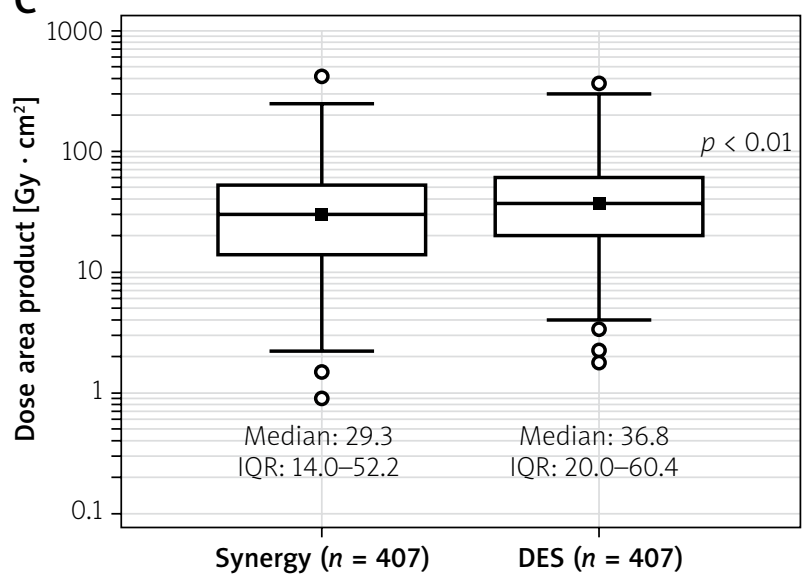

E

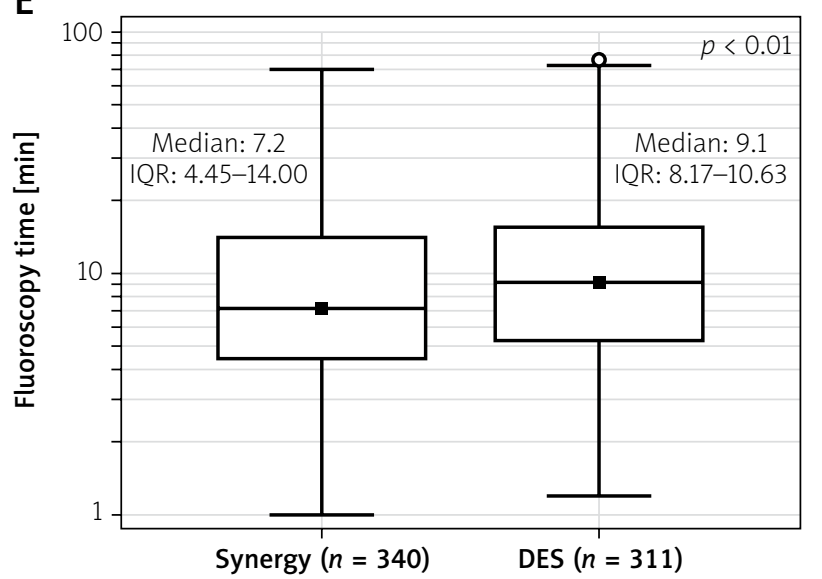

B

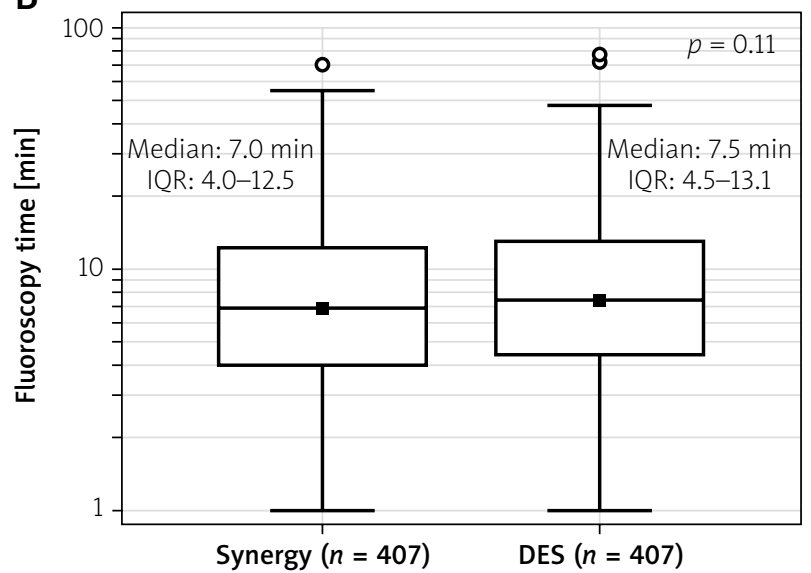

D

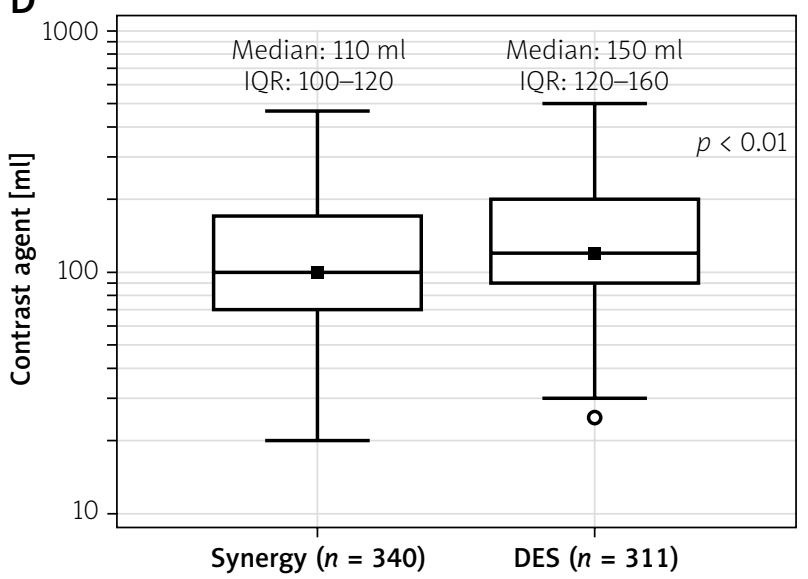

$\mathrm{F}$

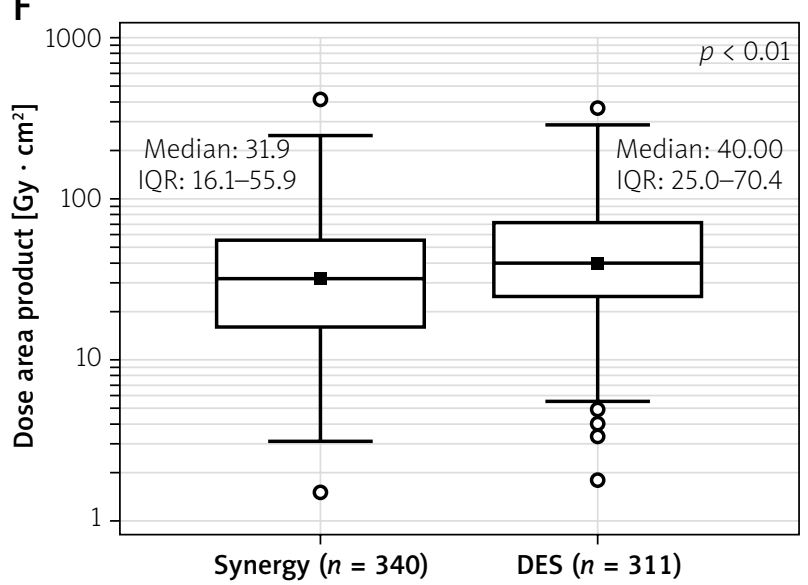

Figure 1. Comparison of contrast agent consumption (A), fluoroscopy time (B), and dose area product (C) between both groups for the entire study population and for those with moderate to severe coronary artery disease (D-F)

$D E S$ - drug-eluting stent, IQR - interquartile range.

ticeable. Some other parameters that can indicate more difficult stent implantations, such as the use of supportive techniques (for example "buddy" or "jailed" wiring), were significantly lower in the Synergy group. And finally, considerably more Synergy stents could be implanted without prior lesion preparation.
All these differences not only indicate enhanced deliverability, but could also potentially improve patients' safety as a consequence of limited manipulation, shorter fluoroscopy time and less injected contrast medium. In addition, this may have economic implications, since less time and fewer materials are needed for a complex procedure. 
Table III. Procedural data

\begin{tabular}{|c|c|c|c|c|}
\hline Parameter & Study population & Synergy & Control & $P$-value \\
\hline \multicolumn{5}{|l|}{ Access site, $n(\%)$ : } \\
\hline Radial & $378(46.4)$ & $196(48.2)$ & $182(44.7)$ & \multirow[t]{2}{*}{0.33} \\
\hline Femoral & $436(53.6)$ & $211(51.8)$ & $225(55.3)$ & \\
\hline \multicolumn{5}{|l|}{ Procedure data: } \\
\hline Contrast agent, median (IQR) [ml] & $110(80-190)$ & $100(70-170)$ & $120(90-200)$ & $<0.01$ \\
\hline Fluoroscopy, median (IQR) [min] & $7.0(4.2-13.0)$ & $7.0(4.0-12.5)$ & $7.5(4.5-13.1)$ & 0.11 \\
\hline Dose area product, median (IQR) [Gy $\left.\cdot \mathrm{cm}^{2}\right]$ & $33.8(17.0-57.15)$ & $29.3(14.0-52.2)$ & $36.8(20.0-60.4)$ & $<0.01$ \\
\hline Procedure data (Stenosis B2 and C): & $n=651$ & $n=340$ & $n=311$ & \\
\hline Contrast agent, median (IQR) [ml] & $120(85-200)$ & $110(100-120)$ & $150(120-160)$ & $<0.01$ \\
\hline Fluoroscopy, median (IQR) [min] & $8.1(5-15)$ & $7.2(4.45-14.00)$ & $9.1(8.17-10.63)$ & 0.01 \\
\hline Dose area product, median (IQR) $\left[\mathrm{Gy} \cdot \mathrm{cm}^{2}\right]$ & $36.85(20.0-61.7)$ & $31.9(16.1-55.9)$ & $40.0(25.0-70.4)$ & $<0.01$ \\
\hline \multicolumn{5}{|l|}{ Technical features: } \\
\hline Rotational atherectomy & $48(5.9)$ & $24(5.9)$ & $24(5.9)$ & 1.00 \\
\hline $\mathrm{CTO} \mathrm{PCl}$ & $48(5.9)$ & $21(5.2)$ & $27(6.6)$ & 0.37 \\
\hline Buddy wiring & $169(20.8)$ & $73(17.9)$ & $96(23.6)$ & 0.05 \\
\hline Caged wire & $96(11.8)$ & $34(8.4)$ & $62(15.2)$ & $<0.01$ \\
\hline \multicolumn{5}{|l|}{ Bifurcation stenting: } \\
\hline Culotte technique PTCA & $18(2.2)$ & $11(2.7)$ & $7(1.7)$ & 0.34 \\
\hline T-stenting & $14(1.7)$ & $8(2.0)$ & $6(1.5)$ & 0.59 \\
\hline Stent crush & $74(9.1)$ & $36(8.8)$ & $38(9.3)$ & 0.81 \\
\hline Attempted "final-kiss"-PTCA & $100(12.3)$ & $57(14.0)$ & $43(10.6)$ & 0.14 \\
\hline Successful & $78(9.6)$ & $44(10.8)$ & $34(8.4)$ & 0.23 \\
\hline Failed & $23(2.8)$ & $14(3.4)$ & $9(2.2)$ & 0.29 \\
\hline \multicolumn{5}{|l|}{ Lesion preparation: } \\
\hline Balloon pre-dilation: & $726(89.2)$ & $347(85.3)$ & $379(93.1)$ & $<0.01$ \\
\hline 1 balloon & $529(65.0)$ & $268(65.8)$ & $261(64.1)$ & \\
\hline 2 balloons & $127(15.6)$ & $50(12.3)$ & $77(18.9)$ & \\
\hline$\geq 3$ balloons & $70(8.6)$ & $29(7.1)$ & $41(10.1)$ & \\
\hline Balloon post-dilation & $396(48.6)$ & $218(53.6)$ & $178(43.7)$ & $<0.01$ \\
\hline \multicolumn{5}{|l|}{ Number of stents per patient: } \\
\hline 1 stent & $297(36.5)$ & $157(38.6)$ & $140(34.4)$ & \multirow[t]{6}{*}{0.49} \\
\hline 2 stents & $223(27.4)$ & $108(26.5)$ & $115(28.3)$ & \\
\hline 3 stents & $195(24.0)$ & $99(24.3)$ & $96(23.6)$ & \\
\hline 4 stents & $69(8.5)$ & $31(7.6)$ & $38(9.3)$ & \\
\hline 5 stents & $21(2.6)$ & $7(1.7)$ & $14(3.4)$ & \\
\hline 6 stents & $9(1.1)$ & $5(1.2)$ & $4(1.0)$ & \\
\hline Stent types: & $n=1,763$ & $n=859$ & $n=904$ & \\
\hline SYNERGY, $n(\%)$ & $859(48.7)$ & $859(100)$ & - & - \\
\hline DES, $n(\%):$ & $904(51.3)$ & & $904(100)$ & \\
\hline Xience Prime & & - & $462(51.1)$ & \multirow[t]{3}{*}{$<0.01$} \\
\hline Promus Element Plus & & - & $317(35.1)$ & \\
\hline Resolute Integrity & & - & $125(13.8)$ & \\
\hline Stent length [mm]: & & & & 0.12 \\
\hline SYNERGY & $20.0 \pm 8.8$ & $20.0 \pm 8.8$ & - & \\
\hline DES: & $19.5 \pm 8.4$ & - & $19.5 \pm 8.4$ & \\
\hline Xience Prime & & - & $20.8 \pm 9.4$ & \\
\hline Promus Element Plus & & - & $18.5 \pm 7.2$ & \\
\hline Resolute Integrity & & - & $17.7 \pm 6.7$ & \\
\hline
\end{tabular}

CTO - chronic total occlusion, DES - drug-eluting stent, IQR - interquartile range, $P C I$ - percutaneous coronary intervention, PTCA - percutaneous transluminal coronary angioplasty. 
Table IV. In-hospital major adverse cardiac and cerebrovascular event (MACCE)

\begin{tabular}{lccc} 
Parameter & Synergy & $2^{\text {nd }}$ gen DES & $P$-value \\
\hline Myocardial infarction* $n(\%)$ & $4(1.0)$ & $8(2.0)$ & 0.25 \\
\hline Stent thrombosis, $n(\%)$ & $2(0.5)$ & $2(0.5)$ & - \\
\hline Re-PCl target lesion, $n(\%)$ & $2(0.5)$ & $2(0.5)$ & - \\
\hline Cardiac death, $n(\%)$ & $11(2.7)$ & $8(2.0)$ & 0.49 \\
\hline Non-cardiac death, $n(\%)$ & $5(1.2)$ & $7(1.7)$ & 0.56 \\
\hline Stroke, $n$ (\%) & $1(0.2)$ & $1(0.2)$ & -
\end{tabular}

*Assessed only for patients with normal baseline troponin levels.

\section{Conclusions}

In this all-comers, real-world $\mathrm{PCl}$ registry, novel coronary stent design advances including ultra-thin struts and abluminal bioabsorbable polymer coating are associated with improved deliverability as compared to currently established second-generation drug-eluting stents with comparable in-hospital rates of major adverse cardiac and cerebrovascular events between the two groups. This may have a positive impact on patients' safety and economic efficiency. These findings will have to be confirmed in future randomized trials, which should be justified by these encouraging results.

\section{Conflict of interest}

HAS and RB received travel support from Boston Scientific. RB received speaker's honoraria from Boston Scientific. The other authors have no conflict of interests to declare.

\section{References}

1. Kastrati A, Mehilli J, Dirschinger J, et al. Intracoronary stenting and angiographic results: strut thickness effect on restenosis outcome (ISAR-STEREO) trial. Circulation 2001; 103: 2816-21.

2. Foin N, Lee RD, Torii R, et al. Impact of stent strut design in metallic stents and biodegradable scaffolds. Int I Cardiol 2014; 177: 800-8.

3. Sullivan TM, Ainsworth SD, Langan EM, et al. Effect of endovascular stent strut geometry on vascular injury, myointimal hyperplasia, and restenosis. J Vasc Surg 2002; 36: 143-9.

4. Hara H, Nakamura M, Palmaz JC, et al. Role of stent design and coatings on restenosis and thrombosis. Adv Drug Deliv Rev 2006; 58: 377-86.

5. Briguori C, Sarais C, Pagnotta P, et al. In-stent restenosis in small coronary arteries: impact of strut thickness. J Am Coll Cardiol 2002; 40: 403-9.

6. Farb A, Weber DK, Kolodgie FD, et al. Morphological predictors of restenosis after coronary stenting in humans. Circulation 2002; 105: 2974-80.

7. Timmins LH, Miller MW, Clubb FJ, et al. Increased artery wall stress post-stenting leads to greater intimal thickening. Lab Invest 2011; 91: 955-67.

8. Stettler C, Wandel S, Allemann S, et al. Outcomes associated with drug-eluting and bare-metal stents: a collaborative network meta-analysis. Lancet 2014; 370: 937-48.
9. Dawkins KD, Grube E, Guagliumi G, et al.; TAXUS VI Investigators. Clinical efficacy of polymer-based paclitaxel-eluting stents in the treatment of complex, long coronary artery lesions from a multicenter, randomized trial: support for the use of drug-eluting stents in contemporary clinical practice. Circulation 2005; 112: 3306-13.

10. Camenzind E, Steg PG, Wijns W. Stent thrombosis late after implantation of first-generation drug-eluting stents: a cause for concern. Circulation 2007; 115: 1440-55.

11. Nordmann AJ, Briel M, Bucher HC. Mortality in randomized controlled trials comparing drug-eluting vs. bare metal stents in coronary artery disease: a meta-analysis. Eur Heart J 2006; 27: 2784-814.

12. Lagerqvist B, James SK, Stenestrand U, et al.; SCAAR Study Group. Longterm outcomes with drug-eluting stents versus bare-metal stents in Sweden. N Engl J Med 2007; 356: 1009-19.

13. Joner M, Finn AV, Farb A, et al. Pathology of drug eluting stents in humans: delayed healing and late thrombotic risk. J Am Coll Cardiol 2006; 48: 193-202.

14. Koppara T, Joner M, Bayer G, et al. Histopathological comparison of biodegradable polymer and permanent polymer based sirolimus eluting stents in a porcine model of coronary stent implantation. Thromb Haemost 2012; 107: 1161-71.

15. Kang SH, Park KW, Kang DY, et al. Biodegradable-polymer drug-eluting stents vs. bare metal stents vs. durable-polymer drug-eluting stents: a systematic review and Bayesian approach network meta-analysis. Eur Heart J 2014; 35: 1147-58.

16. Finn $A V$, Joner $M$, Nakazawa $G$, et al. Pathological correlates of late drug-eluting stent thrombosis: strut coverage as a marker of endothelialization. Circulation 2007; 115: 2435-41.

17. Daemen J, Wenaweser P, Tsuchida K, et al. Early and late stent thrombosis of sirolimus-eluting and paclitaxel-eluting stents in routine clinical practice: data from a large two-institutional cohort study. Lancet 2007; 369: 667-78.

18. Meredith IT, Verheye S, Dubois CL, et al. Primary endpoint results of the EVOLVE trial: a randomized evaluation of a novel bioabsorbable polymer coated, everolimus-eluting coronary stent. J Am Coll Cardiol 2012; 59: 1362-70.

19. Meredith IT, Verheye S, Weissman NJ, et al. Six-month IVUS and two-year clinical outcomes in the EVOLVE FHU trial: a randomised evaluation of a novel bioabsorbable polymer-coated, everolimus-eluting stent. Eurointervention 2013; 9: 308-15.

20. Kereiakes DJ, Meredith IT, Windecker S, et al. Efficacy and safety of a novel bioabsorbable polymer-coated, everolimus-eluting coronary stent: the EVOLVE II Randomized Trial. Circ Cardiovasc Interv 2015; 8: pii: e002372.

21. Wilson GJ, Huibregtse BA, Pennington DE, et al. Comparison of the SYNERGY with the PROMUS (XIENCE V) and bare metal and polymer-only element control stents in porcine coronary arteries. Eurointervention 2012; 8: 250-7.

22. Sianos G, Morel MA, Kappetein AP, et al. The SYNTAX Score: an angiographic tool grading the complexity of coronary artery disease. Eurolntervention 2005; 1: 219-27.

23. Escaned J, Collet C, Ryan N, et al. Clinical outcomes of stateof-the-art percutaneous coronary revascularization in patients with de novo three vessel disease: 1-year results of the SYNTAX II study. Eur Heart J 2017; 38: 3124-34. 